have direct physical, chemical or biological meaning in the natural world, and should be measurable quantities.

In contrast to empirical-statistical models, forward models of formation of natural archives can explicitly account for potential time-dependent biases and errors, such as diagenesis in sediment-based proxies, or changing replication and age/ size trend in tree rings. Moreover, by using process models, the reconstructions can finally make use of all the known climate information contained in the proxies and thus benefit from their wider Earth System context (e.g., atmospheric composition, effects of Milankovitch variations, temperature vs. moisture influence, temperature vs. salinity effects). This extends their applicability and reduces the risk of violating the uniformitarian principle.

These forward models have another very important advantage. They can be invaluable in developing new and more complete ways of evaluating and present- ing all kinds of errors associated with reconstructions of past climate. As both Guiot et al. (2009) and Hughes and Ammann (2009) point out, a number of approaches to achieve this are available or are under active development (Li et al., in press) (Fig. 2). These range from largely data-driven approaches to those that explicitly combine existing understanding of natural archive formation (that is, forward models) and of climate with treatment of multiple sources of uncertainty (e.g., Bayesian hierarchical approaches). Both providers and users of proxy climate records must be jointly engaged in the development of these techniques.

\section{Final thoughts}

We do not propose the abandonment of present methods but rather an expansion of the toolkit PAGES scientists have available. The approaches used in many parts of paleoclimatology were developed 30 or 40 years ago, and were creative and productive responses to the situation we faced then. We now have a much richer set of records, a more diverse and powerful set of tools for analyzing and using them, and benefit from great advances in knowledge of the workings of the climate system. Let's find ways to incorporate this improved understanding of how natural archives are formed into the exploration of the past, using the tools and concepts available in the $21^{\text {st }}$ century!

\section{References}

Guiot, J., Wu, H.B., Garreta, V., Hatte, C. and Magny, M., 2009: A few prospective ideas on climate reconstruction: from a statistical single proxy approach towards a multi-proxy and dynamical approach, Climate of the Past, 5: 571-583.

Hughes, M.K. and Ammann, C.M., 2009: The Future of the Past-an Earth System Framework for High Resolution Paleoclimatology: Editorial Essay, Climatic Change, 94: 247-259.

Li, B., Nychka, D.W. and Ammann, C.M., in press: The value of multiproxy reconstruction of past climate, The Journal of the American Statistical Association, Case Studies Section.

For full references please consult:

http://www.pages-igbp.org/products/newsletters/ref2010_2.html

\title{
Workshop on modeling Holocene climate evolution
}

\section{Bremen, Germany, 16 June 2010}

\section{GERRIT LOHMANN AND WORKSHOP PARTICIPANTS}

Alfred Wegener Institute for Polar and Marine Research, Bremerhaven, Germany; Gerrit.Lohmann@awi.de

The major objective of this workshop was to investigate the spatio-temporal pattern of Holocene climate changes as derived from transient integrations with climate models of different complexity; from comprehensive global climate models to models of intermediate complexity and statistical-conceptual models. For the 23 participants from Germany, The Netherlands, Switzerland and Norway, this was the first step in comparing data with mod- els and may develop into a benchmark for models used in the assessment of future climate change. The Priority Research Program "Integrated analysis of interglacial climate dynamics" (INTERDYNAMIC; www.interdynamik.de; funded by the German Research Foundation; Schulz and Paul, 2009) formed the framework for the workshop. INTERDYNAMIC is based on an integrated approach in paleoclimate research, in which all available paleoclimate

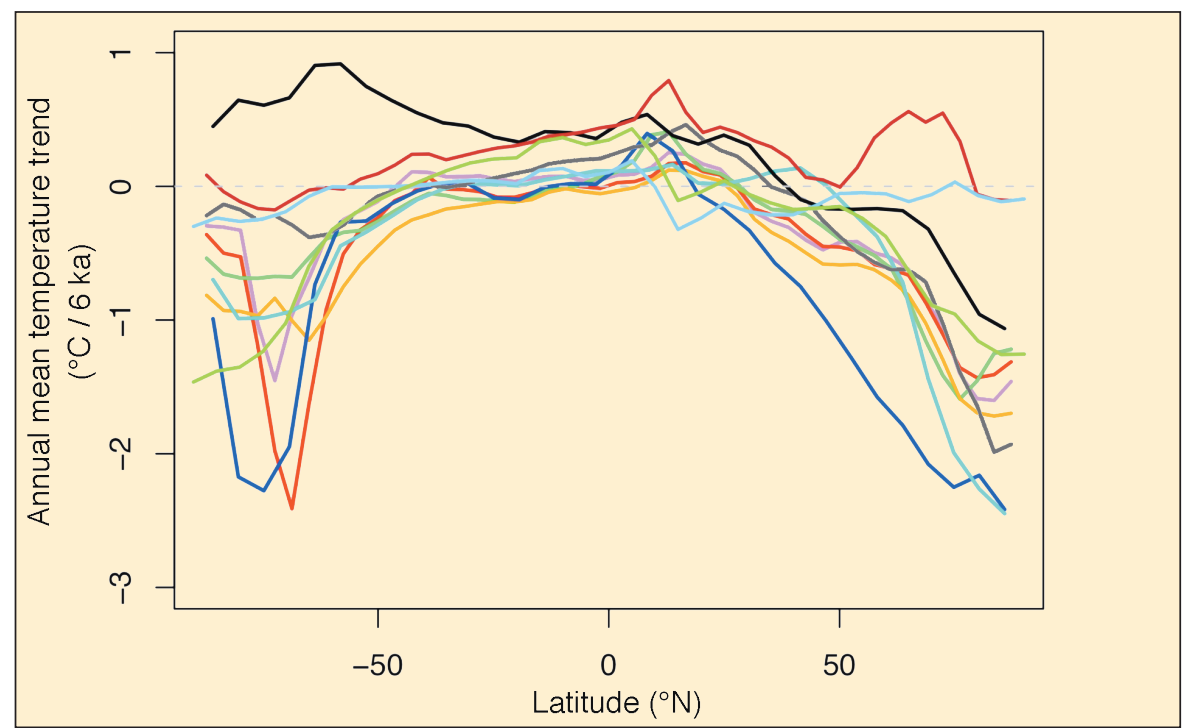

Figure 1: Zonal mean temperature trend from $6 \mathrm{ka} B P$ to the pre-industrial climate as obtained from different climate simulations, forced by Earth's orbital parameters and fixed levels of greenhouse gas concentrations. Most models show a high latitude cooling and low latitude warming. In an upcoming manuscript, it will be disclosed which model shows which temperature trends.

archives are combined with results from Earth System models to gain insights into the dynamics of climate variations during interglacials.

For the paleomodel intercomparison, we compared the results from scenarios with identical forcing for the mid- to lateHolocene period: varying Earth's orbital parameters, fixed level of greenhouse gas concentrations, fixed land-sea mask and orography. All major paleoclimate modeling groups in Germany are involved in this initiative, as well as some European groups working on transient Holocene simulations. Members of the Paleoclimate Dynamics Group at the Alfred Wegener Institute for Polar and Marine Research in Bremerhaven created a data set for the available transient simulations. Posters were prepared in advance, allowing for comparison of the results with common analyses programs and discussions on the results. In addition to participation by the paleoclimate modeling community, some colleagues from the data reconstruction side were also involved. One major issue, affecting both the modeling and reconstruction side, is the quantification of uncertainties and the evaluation of trend and variability patterns beyond a single proxy and beyond a single model simulation. The goal is now to obtain robust results of 
trend patterns, seasonality changes, and transitions on a regional scale.

Currently, nine different model simulations are available (and will be made publically available through the PANGAEA database at http://www.pangaea.de/). A preliminary analysis shows common patterns of temperature changes (Fig. 2). More analysis is necessary to clarify the model differences in response to orbital forcing. Using statistical analysis of the model results, variability modes and their amplitude during the Holocene are identified in the model experiments. Our analyses reveal heterogeneity in temperature and precipitation trends and yield a quantification of robust features in the models. The variations in the large-scale atmosphere-ocean circulation and feedback mechanisms between the components of the climate system will be investigated in the future. Further analysis will also include the development of Southern Hemisphere wind and vegetation changes. We invite the paleoclimate community to participate in this initiative. Those that are interested are invited to email the author to obtain the required transient simulations and data information.

\section{References}

Schulz, M. and Paul, A., 2009: Integrated analysis of interglacial climate dynamics - INTERDYNAMIC Status Seminar, PAGES news, 17 $84-85$.

\title{
Advances in varved sediment studies during the last 10 years
}

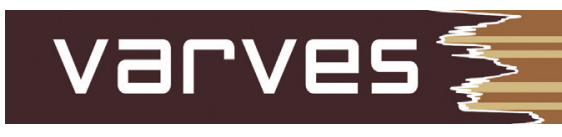

\section{$1^{\text {st }}$ PAGES Varves Working Group workshop, Palmse, Estonia, 7-9 April 2010}

\author{
Pierre Francus ${ }^{1}$, A.E.K. Ojala ${ }^{2}$, A. Heinsalu ${ }^{3}$, R. Behl4, M. Grosjean ${ }^{5}$ and B. Zolitschka ${ }^{6}$ \\ 'National Institute of Scientific Research, Québec, Canada; pfrancus@ete.inrs.ca \\ ${ }^{2}$ Geological Survey of Finland, Espoo; Institute of Geology, Tallinn University of Technology, Estonia; ${ }^{4}$ California State University, Long Beach, \\ USA; ${ }^{5}$ University of Bern, Switzerland; ${ }^{6}$ University of Bremen, Germany
}

A varve is a sequence of layers deposited in a water body within 1 year. Therefore, varved sequences have been the object of a lot of attention from the paleoscience community because they can provide the highest-resolution paleoenvironmental and paleoclimatic records with accurate chronologies independent of radiocarbon reservoir complications and because they enable one to resolve interannual trends in average and even seasonal climate. Iconic paleoclimatic records, such as the Cariaco Basin or Holzmaar in the German Eifel, are famous varved sequences.

Recently, the PAGES Varves Working Group (VWG) was established within the frame of Cross-Cutting Theme 1 (Chronology) and 2 (Proxy development, calibration, validation) to provide a further impetus for the study of varved sediments. The VWG has the objectives of reviewing what has been accomplished during the last 10 years in terms of new methodological developments and improvements in calibration of records, as well as making an inventory of varved records. Other VWG topics are detailed at http://www.pages.unibe. ch/science/varves/index.html

A group of 41 scientists from 11 countries (including 8 students and 4 young scientists) met for the first VWG workshop in the Palmse Manor House, in Lahemaa National Park Centre, Estonia. The workshop was divided into four oral and one poster sessions (for abstract volume see http:// www.pages.unibe.ch/science/varves/ publications.html). The first session was devoted to the study of the processes responsible for the formation (and preservation) of varves from various environments

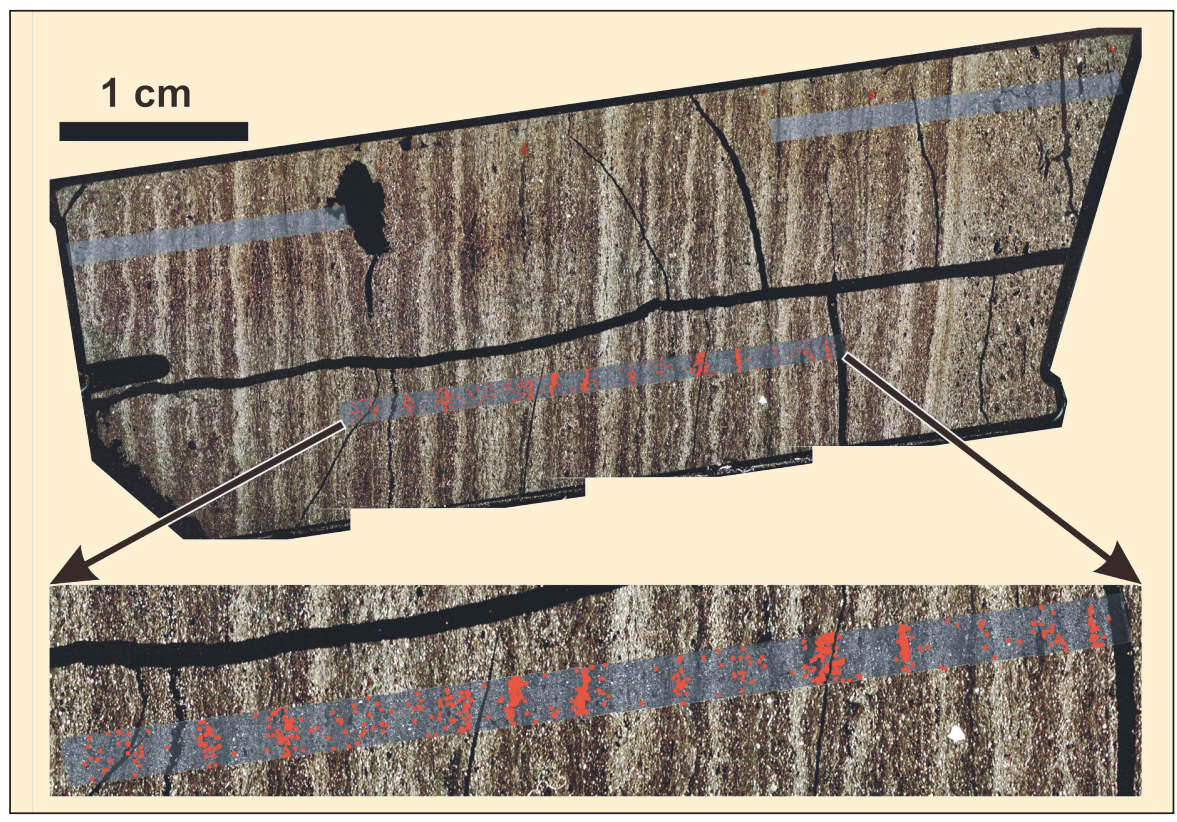

Figure 1: Microscopic view of varved sediments from Lower Mystic Lake, Massachusetts, USA in thin-section (crossedpolarized light). Superimposed grey bands are mosaics of scanning electron microscope images acquired in backscattered mode and used to identify the individual occurrence of the diatom Cyclotella (red dots), which indicates spring blooms and hence confirms the annual character of these laminations. Figure from M.R. Besonen.

in the Canadian Arctic, Western Europe and the Middle East. The second session reviewed advances in the improvement of chronologies of varved records using independent dating techniques, such as paleomagnetic secular variation, tephra horizons and radiocarbon dating, as well as the detailed analysis of internal structures of varves (Fig. 2). The third session was devoted to technological advances in the study of varved and other laminated sediments. It focused on the increasing application of micro-XRF techniques and the development of new softwares helping scientists in the analysis of the large datasets obtained by varve counting. Environmental and climate history case studies from lacustrine and marine sites were discussed during the fourth session. During the poster session, covering all the topics mentioned above, authors briefly introduced their papers to the group.

The workshop participants discussed several practical topics during 3 plenary sessions. They first identified the needs of the VWG community, which included the need for advertising methodological and technical services that can be provided from within the community (e.g., making of thin-section), establishing standards for best practice, promoting systematic comparison of methods, and organization of specialized training courses (e.g., spectral analysis, Bayesian chronological correc- 